\title{
In-silico molecular docking study of novel derivatives of erlotinib in glioma
}

\author{
Deepika Tripathi, Sabiha Imran ${ }^{*}$ \\ Department of Biotechnology, Manav Rachna International Institute of Research and Studies, Faridabad, Haryana, India
}

Received 19th September 2019 / Accepted 17th January 2020

\begin{abstract}
Gliomas are primary brain tumours arises from the glial cells. Gliomas associated risk factor depend upon its degree of stage and grade. Erlotinib is a quinazoline derivative and antineoplastic agent that capacities as a Protein Kinase Inhibitor for Epidermal growth factor receptor (EGFR) related tyrosine kinase and widely used for treating non-small cell carcinoma. Erlotinib, (a tyrosine kinase inhibitor) has been found in the glioblastoma. ErbB (EGF family receptor tyrosine kinase) established to control cell survival, proliferation, migration, and differentiation. The ErbB receptor accounts for the restricted and redundant functions in the maintenance of tissues in adult mammals. Newly discovered drug targets and personalised treatments could be used to identify the characteristics of any individual's tumorigenesis. To see the binding mode of deferent classes of erlotinib carefully chosen based on the structural comparison, we employed simulated screening and molecular docking based on the theory of evolution. The study consists of a simulated screening of around 3200 molecular derivatives of erlotinib and their molecular docking using a Lamarckian genetic algorithm. Molecular docking results showed binding energy ranging from $-12.15 \mathrm{kcal} / \mathrm{mol}$ to $-1.17 \mathrm{kcal} / \mathrm{mol}$. Top 10 best-docked proteins were analyzed using UCSF Chimera and finding discovered the complicated atomic-scale properties between ligand and the target protein. Further wet lab study requires to study the actual binding as binding mode provided. To identify new inhibitors of EGFR with higher potency and specificity, additional information is needed for future designs molecules.
\end{abstract}

Keywords: Molecular docking, EGFR, erlotinib, glioblastoma

\section{INTRODUCTION}

Cancer has been established as a major health problem globally, which impacts more than 8 million death annually (Ferlay et al., 2012). Brain tumours nearly represent $2 \%$ among all type of cancer and $90 \%$ of the central nervous system (Board PATE, 2019). On an estimate, gliomas represent almost $70 \%$ among all brain tumours and shown a high incident in adults (Ostrom et al., 2014). Glioblastoma multiforme (GBM) is known as a rapid growing glioma represents about 55\% of total gliomas and $20 \%$ of whole-brain tumours (Urbańska, et al., 2014). GBM falls under the fifth grade most invasive and deadly tumours. Surgery and radiation are commonly known as treatment strategies (Stupp et al., 2006). GBM generally found to be highly chemo resistive in nature, so the therapeutic intervention is confined and majorly restricted (Villano et al., 2009). There is a high demand to finds out new drug opportunities for a better cure. Widely accepted transmembrane tyrosine kinase receptor accomplishes the critical role in glioma neoplasia, upon activation the receptor transduces the signal for the cell proliferation and survival. To create a new

*Author for correspondence: Sabiha Imran, Department of Biotechnology, Manav Rachna International Institute of Research and Studies, Faridabad, Haryana, India. Email - sabiha.fet@mriu.edu.in 
therapeutic approach signalling cascades for this receptor should be obstructed. Most importantly, Raf/Ras/Mek/Erk and mTOR/Akt/PI3K pathways are having the decisive role for the signalling cascade.

EGFR was primarily sequenced receptor that possesses amino acid enzyme activity (Wells, 1999). ErbB/HER belongs to the receptor tyrosine kinases family consisting of EGFR/ErbB1/HER1, ERBB2/HER2, ERBB3/HER3 and ERBB4/HER4 (Ferley et al., 2008; Stupp et al., 2006). EGFR overexpression has been identified in many cancers like breast, lung, pancreas, and glioblastoma. However, HER2 has been found overexpressed in breast and ovarian cancers (Hudis 2007; Citri \& Yarden 2006; Davies \& Samuel 2010). EFGR overexpression can be seen in non-small-cell lung cancer; moreover, a mutation in these EFGR will help develop targeted cancer therapy (Hudis 2007; Bowers et al., 2001; Paez, 2004; Gharwan \& Groninger, 2016). HER2 copy number has been amplified in 20\%-30\% breast carcinoma (Hudis, 2007). Long exposure of erlotinib could lead to downregulate the EGFR expression along with its molecular invasion effectors in brain tumour cell line culture (Lal et al., 2002). The last phase II clinical trial of erlotinib was well accepted in glioblastoma therapy and showed a modest undeniable control above placebo (Wen et al., 2014). The capability of erlotinib is highly characterised in other cancer cell lines and found to obstruct cell cycle by initiating G1/S phase arrest (Moyer et al., 1997; Quatrale et al., 2011)

In pre-clinical trials, erlotinib showed striking impression by repressing anchorage-independent development in tumor cells lines (Halatsch et al., 2004). According to previous research, outcomes underscore the thought that distinctions in tissueexplicit science as well as the signalling system coupled to EFGR incredibility impact TK1 adequacy. So, we draw the attention to identify new inhibitors of EGFR with higher potency and specificity to tackle receptor tyrosine kinase.

\section{MATERIALS AND METHODS}

\section{Ligand generation}

2D equivalent structural derivatives of $\mathrm{N}$-(3Ethynylphenyl)-6, 7-bis (2-methoxy ethoxy) quinazoline-4-amine were acquired from PubChem. By using inbuilt similarity fingerprinting search, we selected the molecule which got the highest score of 0.68 . This search provides a total of 3200 ligands in which only 500 ligands were tested on the basis of their chemoinformatics analysis. The software Chem Sketch was utilized for generating and sketching MDL Molfile (v2000) molecules; then the ligands were changed into protein databank formats (PDB) using Open Bebel software.

\section{Target or receptor protein}

PDB crystal structure of EGFR tyrosine kinase domain with novel inhibitor downloaded from RCBS (http://www.rcsb.org) using PDB ID: 5JEB. The devoted ligands were separated and energy minimisation implemented by the optimized protocol of Swiss PDB viewer (Guex \& Peitsch 1997).

\section{Docking setup}

Docking studies of protein and ligand had been performed by utilising Auto Dock software version 4 (Moris et al., 2009) which shows binding energy analysis through grid and energy potential using various search algorithms to find out exact binding characteristics on given super molecule. Polar hydrogen molecules are added to the ligand by using AutoDock hydrogen module. A standard procedure was used for the distribution of the Kollman united partial atom charges which involved at random places with the population size of 150.

The result was the clustered rendering $1 \AA$ root mean square deviation standard with exact ten docking runs. The grid size -12.352* 104.011* 22.946 points and grid positioning of $40 \AA$ ' was selected. The Chimera UCSF was utilized for viewing the coordinates of the docked structure within the range of $5 \AA$ of the molecule-protein interaction. UCSF Chimera can be found at the following URL (www.cgl.ucsf.edu/chimera). The molecules which are displaying least binding energies were assessed for drug-likeness using 
"Rule of five" (RO5) for the detection of possible pharmacokinetics. All molecules are subjected to the study of molecular properties and drug likeness scores.

\section{RESULTS AND DISCUSSION}

Different derivatives of erlotinib were docked using a Lamarckian Genetic Algorithm. Merging an utterly unique algorithm rule for binding site identification and assessment of picturing tool has provided an efficient means to exploit unrevealing the characteristic of binding cavity. Total of 100 molecules were adequately screened on the origin of the structural resemblance of erlotinib. Scoring functions are the mathematical methods used to predict the strength of the non-covalent interaction. In the fields of computational chemistry and molecular modelling scoring functions are fast approximate mathematical methods used to predict the strength of the noncovalent interaction (also referred to as binding affinity) between two molecules after they have been docked. Most commonly, one of the molecules is a small organic compound such as a drug and the second is the biological target such as a protein receptor (Tables $1 \& 2$ ).

For the evaluation of a scoring function, an experimentally observed protein-ligand complex can be used. In structure-based drug design, the RMSD is a measure of the difference between a crystal conformation of the ligand and a docking prediction. Hence for stability, we always look for minimum values.

Typically, if a ligand binds to a protein, the enthalpic term decreases due to favourable intermolecular interactions and the formation of intermolecular bonds. This means whatever molecules giving minimum energy are favourably binding to the active site of the target. In the world of chemical transformations, chemicals always want to minimize their Gibbs free energy. What this means is that chemicals will tend to transform into other states or chemicals that have less Gibbs free energy. For example, Ice will always convert to water when the temperature is above 0 degrees Celsius.

Table 1. Chemical properties of the top 10 molecules out of 500 molecules with the minimum binding energy.

\begin{tabular}{|c|c|c|c|c|}
\hline No. & $\begin{array}{l}\text { PubChem } \\
\text { ID }\end{array}$ & Compound IUPAC name & $\begin{array}{c}\text { Minimum } \\
\text { binding } \\
\text { energy }\end{array}$ & Run \\
\hline 1 & 87471879 & $\begin{array}{l}\text { N-[3-(2-deuterioethynyl)phenyl]-6,7-bis(2- } \\
\text { methoxyethoxy) quinazolin- } 4 \text {-amine }\end{array}$ & -13.13 & 2 \\
\hline 2 & 59772909 & $\begin{array}{l}\text { 6-butoxy-N-(3-ethynylphenyl)-7-(2- } \\
\text { methoxyethoxy) quinazolin - } 4 \text { - amine }\end{array}$ & -13.60 & 9 \\
\hline 3 & 49849306 & $\begin{array}{l}\text { N-(3-ethynylphenyl)-6,7-bis(2-methoxyethoxy) } \\
\text { quinazolin-4-amine hydrochloride }\end{array}$ & -12.67 & 6 \\
\hline 4 & 44609731 & Icotinib Hydrochloride & -12.24 & 6 \\
\hline 5 & 25204422 & $\begin{array}{l}\mathrm{N} \text {-(3-ethynylphenyl)-6,7-bis(2-methoxyethoxy) } \\
\text { quinazolin-4-amine hydroiodide }\end{array}$ & -12.22 & 9 \\
\hline 6 & 16045651 & $\begin{array}{l}\text { N-(5-ethynyl-2-methylphenyl)-6,7-bis(2- } \\
\text { methoxyethoxy) quinazolin-4-amine }\end{array}$ & -11.72 & 1 \\
\hline 7 & 11452930 & $\begin{array}{l}\text { N-(3-ethynylphenyl)-6,7-bis(3- } \\
\text { methoxypropoxy) quinazolin-4-amine }\end{array}$ & -11.52 & 2 \\
\hline 8 & 118919167 & $\begin{array}{l}\text { N-(3-ethynylphenyl)-5-iodo-6,7-bis(2- } \\
\text { methoxyethoxy) quinazolin-4-amine }\end{array}$ & -11.41 & 9 \\
\hline 9 & 91350798 & $\begin{array}{l}\text { N-[3-(3-ethoxy-3-methylbut-1-ynyl)phenyl]-6,7- } \\
\text { bis(2-methoxyethoxy) quinazolin-4-amine }\end{array}$ & -11.38 & 7 \\
\hline 10 & 89265293 & $\begin{array}{l}\text { 2-[6-(2-cyanatoethoxy)-4-(3-ethynylanilino) } \\
\text { quinazolin-7-yl] oxyethyl cyanate }\end{array}$ & -11.37 & 4 \\
\hline
\end{tabular}


Table 2. Chemical structure of the top 10 molecules.

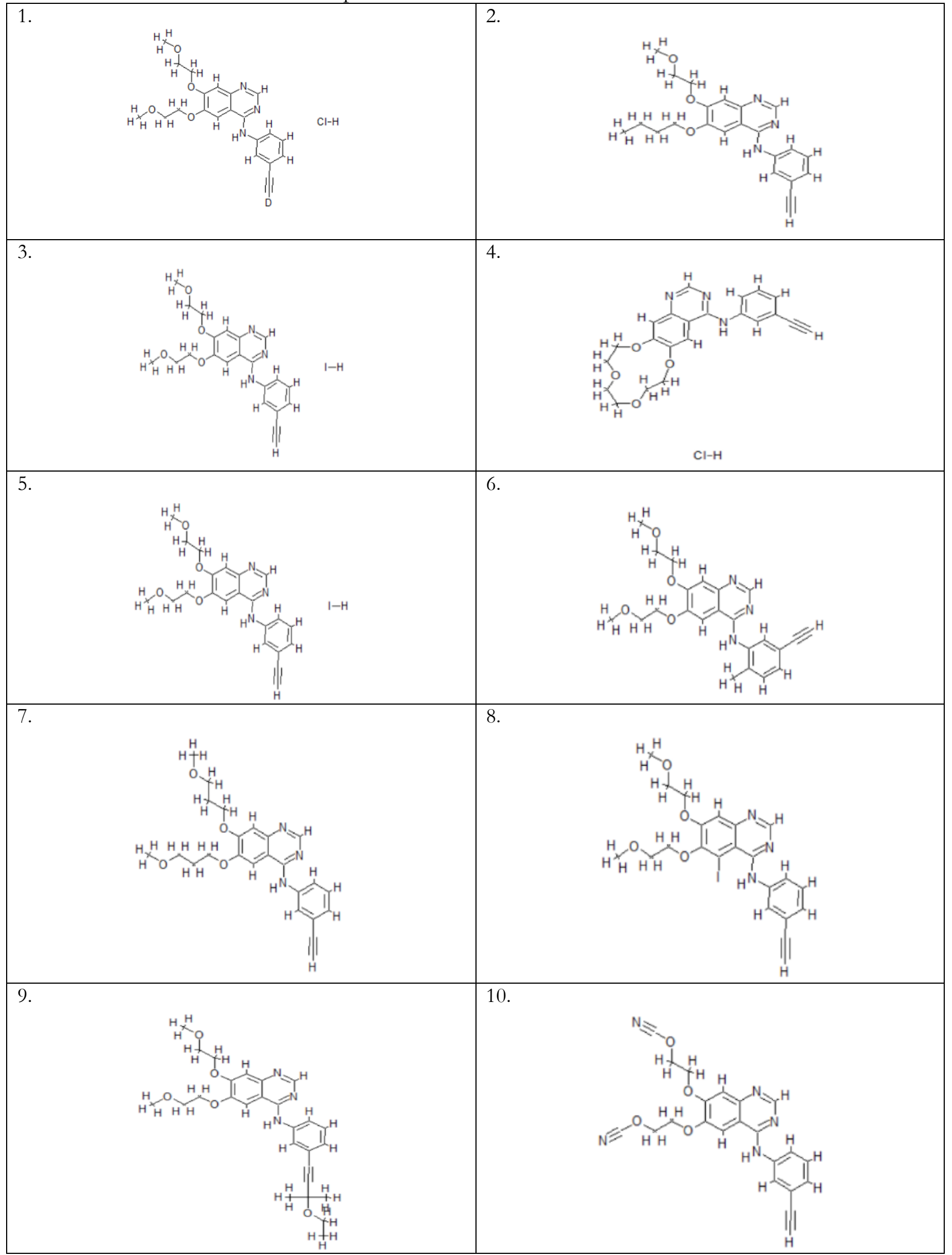




\section{CONCLUSIONS}

The development of the unique biologically active compounds is the necessary need for the developing world. In this study, we successfully docked EFGR protein with erlotinib derivatives to give new insight for drug interaction study. Based on this molecular docking study, we found ten potent molecules consisting of minimum binding energy with having at least one hydrogen bond with the receptor protein. These types of approaches can play a more serious role in the ongoing race of the development of a new drug molecule for hitting new molecular targets. The scope of this work gives the pivotal the binding mode via in-silico practice. Furthermore, it remains highly required to generate such results in wet lab modes to test the new drugs in reality for understanding their better specificity and metabolism.

\section{ACKNOWLEDGEMENTS}

This research work is supported by, Manav Rachna International Institute of Research and Studies, Department of biotechnology, Faridabad, India.

\section{REFERENCES}

Board, P. A. T. E. 2019. Adult Central Nervous System Tumors Treatment (PDQ $\left.{ }^{\circledR}\right)$. In PDQ Cancer Information Summaries. National Cancer Institute (US).

Bowers, G., Reardon, D., Hewitt, T., Dent, P., Mikkelsen, R. B., Valerie, K., \& Schmidt-Ullrich, R. K. 2001. The relative role of ErbB1-4 receptor tyrosine kinases in radiation signal transduction responses of human carcinoma cells. Oncogene 20(11): 1388

Citri, A. \& Yarden, Y. 2006. EGF-ERBB signalling: towards the systems level. Nature Reviews Molecular Cell Biology 7(7): 505.

Davies, M. A. \& Samuels, Y. 2010. Analysis of the genome to personalize therapy for melanoma. Oncogene 29(41): 55455555 .

Ferlay, J., Soerjomataram, I., Ervik, M., Dikshit, R., Eser, S., Mathers, C., et al. 2012. GLOBOCAN v1.0, Cancer Incidence and Mortality Worldwide: IARC CancerBase No. 11.

Gharwan, H. \& Groninger, H. 2016. Kinase inhibitors and monoclonal antibodies in oncology: clinical implications. Nature Reviews Clinical Oncology 13(4): 209.
Guex, N. \& Peitsch, M. C. 1997. SWISS-MODEL and the SwissPdb Viewer: an environment for comparative protein modeling. Electrophoresis 18(15): 2714-2723.

Halatsch, M. E., Gehrke, E. E., Vougioukas, V. I., Bötefür, I. C., Farhad, A., Efferth, T., \& Buchfelder, M. 2004. Inverse correlation of epidermal growth factor receptor messenger RNA induction and suppression of anchorage-independent growth by OSI-774, an epidermal growth factor receptor tyrosine kinase inhibitor, in glioblastoma multiforme cell lines. Neurosurgical Focus 16(2): 1-11.

Hudis, C. A. 2007. Trastuzumab-mechanism of action and use in clinical practice. New England Journal of Medicine 357(1): 39-51.

Lal, A., Glazer, C. A., Martinson, H. M., Friedman, H. S., Archer, G. E., Sampson, J. H., \& Riggins, G. J. 2002. Mutant epidermal growth factor receptor up-regulates molecular effectors of tumor invasion. Cancer Research 62(12): 33353339.

Morris, G. M., Huey, R., Lindstrom, W., Sanner, M. F., Belew, R. K., Goodsell, D. S., \& Olson, A. J. 2009. Autodock4 and AutoDockTools4: automated docking with selective receptor flexiblity. J. Computational Chemistry 16: 2785-91.

Moyer, J. D., Barbacci, E. G., Iwata, K. K., Arnold, L., Boman, B., Cunningham, A., et al. 1997. Induction of apoptosis and cell cycle arrest by CP-358,774, an inhibitor of epidermal growth factor receptor tyrosine kinase. Cancer Research 57(21): 4838 4848.

Ostrom, Q. T., Bauchet, L., Davis, F. G., Deltour, I., Fisher, J. L., Langer, C. E., \& Wrensch, M. R. 2014. The epidemiology of glioma in adults: a "state of the science" review. Neurooncology 16(7): 896-913.

Paez, J. G., Jänne, P. A., Lee, J. C., Tracy, S., Greulich, H., Gabriel, S., Herman, P., Kaye, F. J., Lindeman, N., Boggon, T. J., Naoki, K., Sasaki, H., Fujii, Y., Eck, M. J., Sellers, W. R., Johnson, B. E., Meyerson, M. 2004. EGFR mutations in lung cancer: correlation with clinical response to gefitinib therapy. Science 304(5676): 1497-500.

Quatrale, A. E., Porcelli, L., Silvestris, N., Colucci, G., Angelo, A., Azzariti, A. 2011. EGFR tyrosine kinases inhibitors in cancer treatment: in vitro and in vivo evidence. Frontiers in Bioscience 16: 1962-1972.

Stupp, R., Hegi, M. E., Van den Bent, M. J., Mason, W. P., et al. 2006. Changing paradigms--an update on the multidisciplinary management of malignant glioma. Oncologist 11:165-180.

Urbańska, K., Sokołowska, J., Szmidt, M., \& Sysa, P. 2014. Glioblastoma multiforme-an overview. Contemporary Oncology 18(5): 307.

Lee, V. J., Seery, T. E., \& Bressler, L. R. 2009. Temozolomide in malignant gliomas: current use and future targets. Cancer Chemotherapy and Pharmacology 64(4): 647-655.

Wells, A. 1999. EGF receptor. International Journal of Biochemistry and Cell Biology: 637-43.

Wen, P. Y., Chang, S. M., Lamborn, K. R., Kuhn, J. G., Norden, A. D., Cloughesy, T. F., \& Drappatz, J. 2014. Phase I/II study of erlotinib and temsirolimus for patients with recurrent malignant gliomas: North American Brain Tumor Consortium trial 04-02. Neuro-oncology 16(4): 567-578. 